\title{
Revisiting the Text - A Case of Mucous Extravasation Cyst
} \author{
Kashyap ${ }^{4}$ \\ ${ }^{1}$ Postgraduate Student, Department of Oral Medicine and Radiology, AJ Institute of Dental Sciences, India \\ ${ }^{2}$ Professor, Department of Oral Medicine and Radiology, AJ Institute of Dental Sciences, India \\ ${ }^{3}$ Professor and Head, Department of Oral Medicine and Radiology, AJ Institute of Dental Sciences, India \\ ${ }^{4}$ Reader, Department of Oral Medicine and Radiology, AJ Institute of Dental Sciences, India
}

Reshma Suvarna ${ }^{1^{*}}$, Prasanna Kumar Rao², Raghavendra Kini ${ }^{3}$, Gowri P Bandarkar ${ }^{4}$ and Roopashri Rajesh

Submission: November 23, 2017; Published: May 31, 2018

*Corresponding author: Reshma Suvarna, Postgraduate student, Department of Oral Medicine and Radiology, AJ Institute of Dental Sciences, Karnataka, India, Tel: +919449966216; Email: mailto:itsreshma_11@yahoo.co.in

Abstract

Mucocele is a common lesion of the oral mucosa that results from an alteration of minor salivary glands due to a mucous accumulation, causing mid swelling. Common sites are lip followed by tongue, floor of mouth, buccal mucosa and lower labial mucosa. Seen commonly in children's and young adults. Trauma and lip biting habits are the main cause for these types of lesions. These are painless lesions which can be diagnosed clinically. Various treatment options are available but surgical excision is considered an appropriate treatment modality with least recurrence rate and good prognosis. Here, we report a case of an oral mucocele which was treated with surgical excision with no recurrence.

Keywords: Mucocele; Extravasation cyst; Surgical excision

\section{Introduction}

Mucocele is a mucus filled cyst that can occur in the oral cavity, appedix, gall bladder, paranasal sinuses or lacrimal sac. The term mucocele is derived from a latin word, mucus and cocele means cavity. Mucocele is seventeenth most common salivary gland lesions appearing in the oral cavity, as a result of mucin accumulation due to the alteration in the minor salivary gland which leads to limited swelling [1]. Patients with mucoceles regularly state that the lesion "gets larger, then smaller, then larger again." This is an important diagnostic sign. The mucosa of the lower lip and buccal mucosa are the most common sites, but any area that has intraoral salivary glands is a potential site [2]. Its incidence is generally high, 2.5 per 1000 patients, seen in the second decade of life and is rare among children and infants under one year of age. 6 various literatures on Mucocele reveal that it is equally seen in men and women [3]. Two types of mucocele seen are - extravasation and retention. Extravasation mucocele appears due to broken salivary gland duct and the continuous spillage into the soft tissues around the gland. Retention mucocele is seen due to a decrease or absence of glandular secretion produced by blockage of the gland ducts. If seen on the floor of the mouth these lesions are called ranulas as the inflammation resembles the cheeks of a frog [4].

\section{Case Report}

A medically fit 22-year-old female presented with a painless swelling in the lower labial mucosa, of size $1 \times 1 \mathrm{~cm}$ for more than two years (Figure 1). The swelling was initially small and had slowly increased its size. Patient had also noticed regression of the size of the lesion at times which then regained back its size in no time. There was no history of trauma, parafunctional habits, or history of difficulty or pain during chewing or speaking. On extraoral examination, the face of the patient was bilaterally symmetrical with no remarkable findings. On Intraoral inspection, a solitary, circular well defined swelling was present on lower left buccal vestibular region in relation to tooth number 33and 34 . The swelling extended anterio-posteriorly from mesial surface of 33 to the distal surface of 34; supero-inferiorly it extended from muco-gingival junction of 33,34 to $1 \mathrm{~cm}$ away towards the vestibule onto the buccal mucosa. The swelling measured approximately $3 \times 2 \mathrm{~cm}$ in size and was superficial and oval in shape, it had smooth and shiny surface had slight bluish hue. On palpation, all the inspectory findings were confirmed. The swelling was soft in consistency, non-tender, fluctuant, nonreducible and compressible. On correlating the clinical history with the clinical examination a provisional diagnosis of Mucocele 


\section{Advances in Dentistry \& Oral Health}

on lower labial mucosa with the differential diagnosis of fibroma, lipoma and hemangioma was made. A further investigation like diascopy was found to be negative. Hence lesions of vascular origin were ruled out; therefore excisional biopsy was advised and performed (Figure $2 \& 3$ ). The histopathological finding revealed areas of severance of duct, eosinophilic coagulum and mucous pooling (Figure 4). Correlating the clinical findings with the histopathological report a final diagnosis of Extravasation type of Mucocele in lower labial mucosa was made. Patient was examined after 1 week, post-operatively and was recalled after a period of 1 month wherein no recurrence was noted.

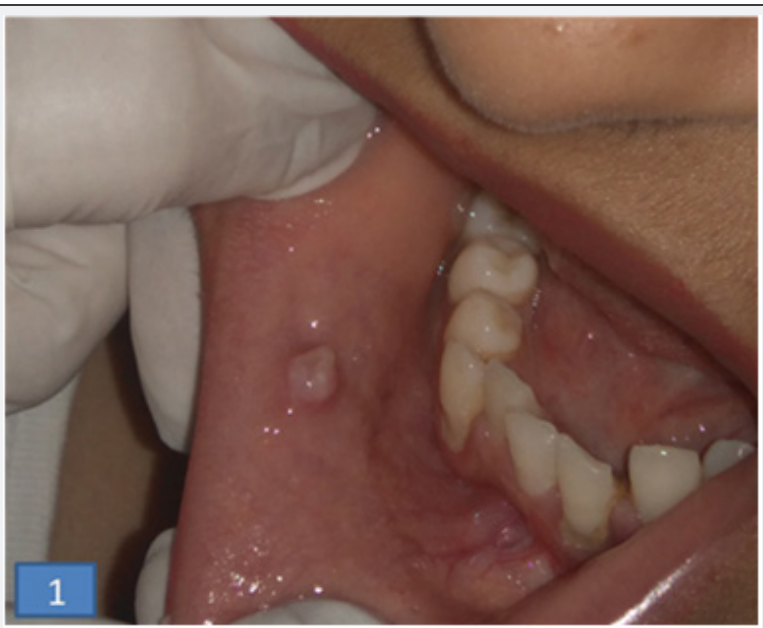

Figure 1: Lesion seen on the lower labial mucosa.
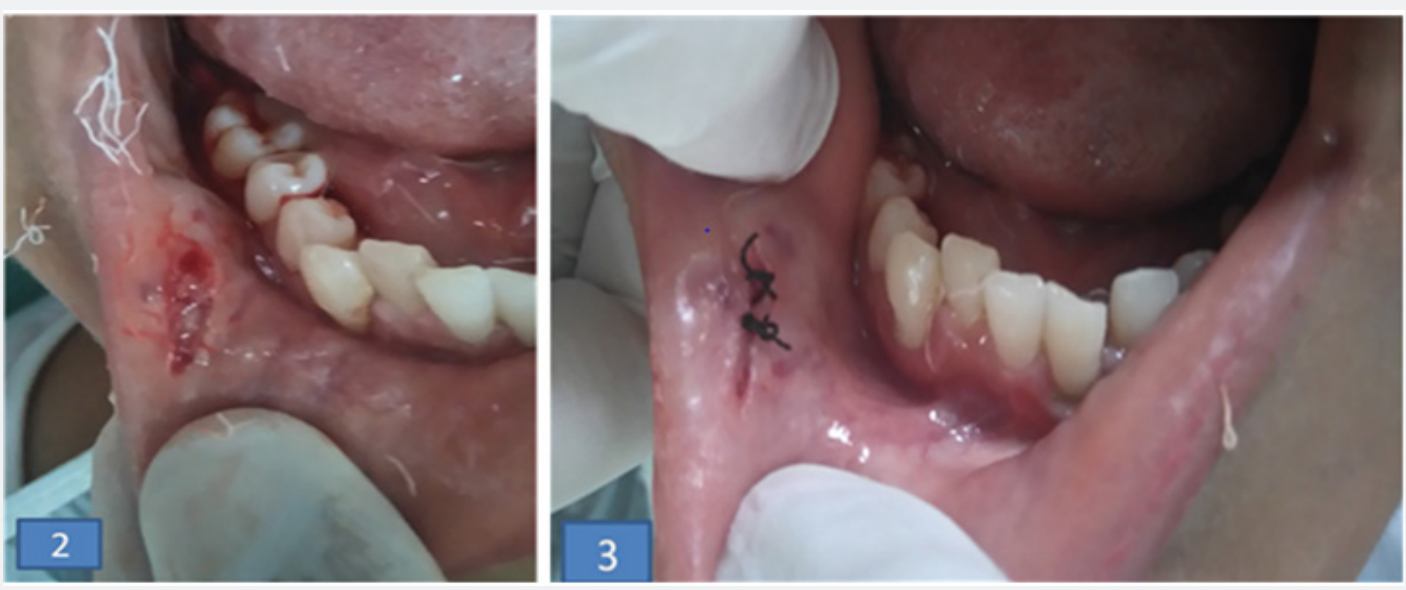

Figure 2\&3 : Surgical excision of the lesion.

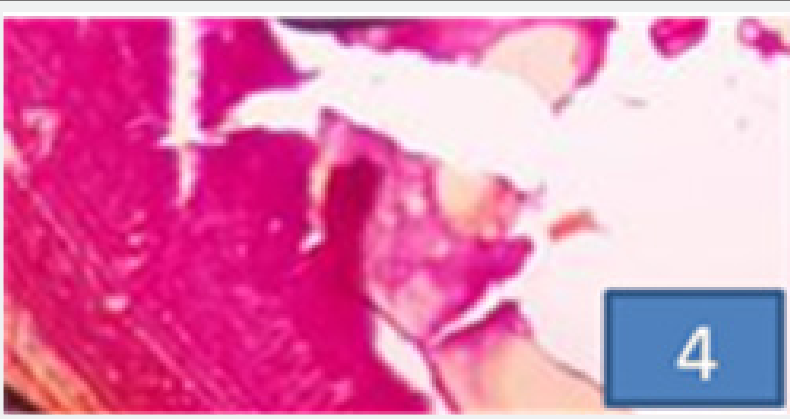

Figure 4: Lesion seen on the lower labial mucosa.

\section{Discussion}

Mucocele is a benign cystic lesion of the oral cavity that has been ranked seventeenth most common salivary gland lesion seen in the oral cavity. It is the second most common benign soft tissue tumor occurring in the oral cavity [1]. The incidence of mucoceles in the general population is $0.4 \%$ to $0.8 \%$ with mnimum differences between genders. Lower lip is the most frequently affected location, followed by the cheek mucosa and floor of the mouth $[5,6]$. Parafunctional habits are also one of the 
aggravating factors. Two common etiological factors are trauma and obstruction of salivary gland duct. Physical trauma cause spillage of salivary secretion into surrounding submucosal tissue and inflammation becomes obvious in later stages due to stagnate mucous [7].

Extravasation mucoceles undergo three evolutionary phases. Firstly, mucous spills diffusely from the excretory duct into conjunctive tissues where some leucocytes and histiocytes are present. Granulomas are seen during the resorption phase due to histocytes, macrophages and giant multinucleated cells associated with a foreign body reaction. And finally connective cells form a pseudocapsule without epithelium around the mucosa. Retention mucoceles are formed by dilation of the duct secondary to its obstruction or caused by a sialolith or dense mucosa. Majority of retention cysts develop in the ducts of major salivary glands [8]. It depends upon the obstruction of salivary flow from secretory apparatus of the gland [1]. Mucocele lesions are devoid of epithelial lining and can also be termed as, superficial mucocele which are located under the mucous membrane and classical mucocele which are seen in the upper submucosa [1]. Diagnosis is primarily clinical; therefore, screening should be carried out properly. The appearance of mucoceles is pathognomonic [9]. Lesion location, history of trauma, rapid appearance, variations in size, bluish colour and the consistency are crucial details [4]. Palpation is helpful for a correct differential diagnosis. Lipomas and tumors of minor salivary glands present no fluctuation while cysts, mucoceles, abscess and hemangiomas show fluctuation [10]. Mucoceles are mobile lesions with soft and elastic consistency [9]. A drained mucocele would not fluctuate and a chronic mucocele with a developed fibrosis will have less fluctuation. Fine Needle Aspiration Biopsy (FNAB) is helpful. A histopathologic study is necessary to confirm the diagnosis.

Conventional treatment surgical extirpation of the surrounding mucosa and glandular tissue upto the muscle layer. With a simple incision of the mucocele the content would drain out but the lesion will reappears soon as the wound heals [11]. Small mucoceles should be removed completely with the marginal glandular tissue before suture. For larger lesions, marsupialization avoids damage to vital structures [4]. Newer treatment modalities like cryosurgery, intralesional steroid injections and $\mathrm{CO}_{2}$ laser are also used. $\mathrm{CO}_{2}$ laser is a perfect surgical treatment for oral soft tissues [4]. As cut is precise and does not affect the muscle layer, leading to minimal haemorrhage and no acute inflammatory reaction [11]. The key point to avoid recurrence is to eliminate the adjacent surrounding glandular acini and removing the lesion upto the muscle layer $[4,11]$. Extra care should be taken to avoid injury to the adjacent glands and ducts while placing sutures as this can be a cause for reappearance [4].

\section{Conclusion}

Mucocele is the most commonly occuring benign self-limiting lesion of the oral mucosa. Trauma being the common cause and mostly seen in lower lips. Majority of these cases can be diagnosed clinically however sometimes biopsy is required to rule out any other types of neoplasm. As there is a possibility that a lesion in this location might be a tumour, hence excision is warranted for definitive diagnosis. Newer treatment options like $\mathrm{CO}_{2}$ laser treatment shows increased benefits and less relapses. As these lesions are painless, it is the dentists, who figures out these lesions when the patient walks in for a routine oral screening or an unrelated dental problem.

\section{References}

1. Rao PK, Hegde D, Shetty SR, Chatra L, Shenai P (2012) Oral Mucocelediagnosis and management. Journal of dentistry, Medicine and Medical sciences 2(2): 26-30.

2. Dunlap Cl, Barker Bf A Guide To Common Oral Lesions. Chapter 16.

3. Marathe S, Hebbal M, Nisa SUl, Harchandani N (2014) Oral Mucocele: Presentation at a Rare Site with Review. Int J Adv Health Sci 1(4): 1418.

4. Ali JA, Carrillo C, Bonet C, Balaguer J, Peñarrocha M, et al. (2010) Oral mucocele: review of the literature. J Clin Exp Dent 2(1): 18-21.

5. Laller S, Saini RS, Malik M, Jain R (2014) An Appraisal of Oral Mucous Extravasation Cyst Case-Mini Review. J Adv Med Dent Scie 2(2): 166170 .

6. Sukhtankar LV, Mahajan B, Agarwal P (2013) Treatment of Lower lip Mucocele with Diode Laser - A Novel Approach. Annals of Dental Research 2(1): 102-108.

7. Kirti C, Arundeep KL, Faraz Farrukh, Tandon Shruti, Arora Shipra, et al. (2010) Treatment of Lower Lip Mucocele with Er,Cr:YSGG Laser - A Case Report, J Oral Laser Applications 10(4): 181-185.

8. Baurmash HD (2003) Mucoceles and ranulas. J Oral Maxillofac Surg 61(3): 369-378.

9. Bentley JM, Barankin B, Guenther LC (2003) A review of common pediatric lip lesions: herpes simplex/recurrent herpes labialis, impetigo, mucoceles, and hemangiomas. Clin Pediatr (Phila) 42(6): 475-482.

10. Guimarães MS, Hebling J, Filho VA, Santos LL, Vita TM, et al. (2006) Extravasation mucocele involving the ventral surface of the tongue (glands of Blandin-Nuhn). Int J Paediatr Dent 16(6): 435-929.

11. Huang IY, Chen CM, Kao YH, Worthington P (2007) Treatment of mucocele of the lower lip with carbon dioxide laser. J Oral Maxillofac Surg 65(5): 855-858. 


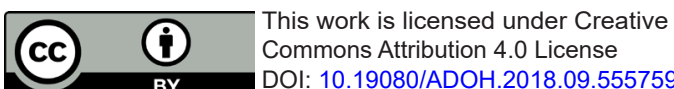

\section{Your next submission with Juniper Publishers} will reach you the below assets

- Quality Editorial service

- Swift Peer Review

- Reprints availability

- E-prints Service

- Manuscript Podcast for convenient understanding

- Global attainment for your research

- Manuscript accessibility in different formats

( Pdf, E-pub, Full Text, Audio)

- Unceasing customer service

Track the below URL for one-step submission https://juniperpublishers.com/online-submission.php 